\title{
Hedônico: o projeto ergonômico afetivo de produtos e sistemas
}

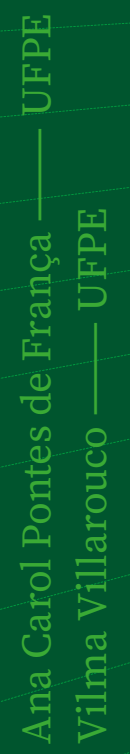




\section{INTRODUÇÃO}

Os avanços no projeto de produtos/sistemas tecnológicos e no desenvolvimento de interfaces estão relacionados às transformações frente ao mercado consumidor, ávido por novidades.

Projetar para que essas novidades tenham um impacto positivo, a ponto das conexões afetivas, usuário-produto, serem suficientemente boas, requer entender a relação consumo-utilização, de modo que o usuário, além de atraído pelo produto/ sistema, continue a utilizá-lo mesmo com o passar dos anos.

Como essas novidades são concebidas para pessoas de carne e osso, o projeto dos produtos/sistemas precisa, além de considerar os contextos de uso, adequar esses produtos/sistemas aos usuários, que se 
distinguem uns dos outros por opiniões e preferências. Nesse sentido, não basta ao produto/sistema ter uma boa aparência ou uma boa usabilidade. É importante "otimizar a relação usuário-produto”. (FALCÃO; SOARES, 2013)

Com o intuito de ir "além das experiências emocionais que o Design pós-moderno propõe, proporcionando também segurança e conforto" (VAN DER LINDEN, 2007, p. 18), o design de interfaces físicas e virtuais de produtos e sistemas passou a considerar parâmetros para o projeto e redesenho com base em princípios, métodos e técnicas da ergonomia.

Fundamentado nas técnicas de avaliação ergonômica do produto/sistema (análise da tarefa, testes de usabilidade, etc.) o projeto ergonômico afetivo destaca os aspectos hedônicos enquanto projeta para o maior número possível de pessoas sem desconsiderar as características e limitações do público-alvo.

Desse modo, é possível prevenir erros e situações de risco que causem dor e sofrimento e ainda tornar o produto/sistema adaptável e significativo para o usuário.

Ou seja, propor novas ideias e projetar produtos/sistemas customizados requer investigar sobre as pessoas e seus hábitos, bem como sobre as necessidades, expectativas e interesses dos usuários.

Nesses termos, para que o projeto orientado aos fatores humanos/ergonômicos seja especial e agradável torna-se indispensável considerar a relação afetiva usuário-produto bem como a importância das emoções na interação humano-tecnologia de modo que o produto seja entendido além da relação física. (VAN DER LINDEN, 2007)

Dito de outra forma, ainda que esteja supostamente se divertindo, ninguém gosta de se sentir apertado, com os movimentos restritos, limitado cognitiva e mentalmente ou mesmo fatigado. Face ao exposto, como avaliar se o usuário estaria de fato tendo uma experiência positiva e prazerosa com a tecnologia? Até que ponto os fatores físicos estariam interferindo na qualidade da experiência? Ainda que ocorram limitações, restrições, até que ponto elas comprometeriam a experiência positiva e prazerosa com o sistema?

Atento a essas e outras questões, este trabalho busca apresentar as relações entre a ergonomia e a hedonomia a fim de discutir sobre as principais características do design hedônico, de modo a não esgotar o assunto, mas torná-lo referência para o desenvolvimento teórico-conceitual, científico e tecnológico. 


\section{A ERGONOMIA E 0 DESIGN HEDÔNICO}

Antes de falar sobre as características do projeto hedônico e sobre os aspectos do processo de design nessa perspectiva, faz-se necessário esclarecer algumas confusões conceituais relacionadas aos termos: Design Centrado no Humano; Design Centrado no Uso; e Design Centrado no Indivíduo.

Esses termos, apesar de semelhantes, guardam características que os diferenciam um do outro, não só do ponto de vista teórico, como prático (CYBIS; BETIOL; FAUST, 2010; HANCOCK; PEPE; MURPHY, 2005):

\section{Design Centrado no Humano}

Considera a primazia das capacidades sensoriais, cognitivas, físicas e motoras do componente humano do sistema, elemento central desde as fases iniciais do processo de design. Por exemplo, se o humano tivesse pinças no lugar das mãos, o modo como perceberia, entenderia e agiria com o produto seria diferente.

\section{Design Centrado no Uso}

Como o próprio nome sugere, concentra-se no uso, ou seja, emerge das ações combinatórias dos humanos no uso da tecnologia. Por exemplo, o telefone foi inicialmente concebido para as pessoas receberem chamadas e falarem umas com as outras, embora as pessoas atualmente usem o telefone para bloquear um contato. 


\section{Design Centrado no Indivíduo}

Característico do projeto hedônico. Concentra-se no nível pessoal e no estado de individualização ${ }^{01}$, relacionados às conexões afetivas dos usuários com os produtos/sistemas.

Essa individualização, no entanto, não se encerra no self (consciência, "eu"), visto que afeta os demais componentes do sistema (por exemplo, o ambiente físico e virtual e as demais pessoas, além dos aspectos inconscientes relacionados à atividade neural). (RACHED; PERKUSICH, 2017; SANTA ROSA; PEREIRA JR; LAMEIRA, 2016; FORSYTHE, 2015; GARCIA-MOLINA; TSONEVA; NIJHOLT, 2013; JOHNSON; PROCTOR, 2013)

Ou seja, no design hedônico são consideradas as características de cada ser humano (capacidades e limitações sensoperceptivas, cognitivas e de resposta). As dimensões pessoais devem ser exploradas e a avaliação deve respeitar as motivações e aspirações do indivíduo.

Como o sistema vivo é o elemento central, o que vai diferenciar a perspectiva hedônica da ergonomia tradicional será a finalidade do projeto que, ao invés de evitar ou tentar curar o negativo (ergonomia tradicional), passa a focar na promoção do positivo.

Em outras palavras, enquanto a ergonomia se concentra em prevenir a dor e o sofrimento, a perspectiva hedônica foca em promover o prazer no sistema humano-tarefa-tecnologia-ambiente (MONT'ALVÃO; DAMAZIO, 2012), o que para Hancock, Pepe e Murphy (2005, p. 10) caracteriza uma "expansão paradigmática".

01 Características que tornam o usuário único e que o diferencia dos demais. 
Figura 1.

Hierarquia das

necessidades

ergonômicas e

hedônicas obtida a

partir da hierarquia

das necessidades de

Maslow. Adaptado

de Hancock, Pepe

e Murphy (2005).

\section{SOBRE O PROJETO \\ ERGONÔMICO AFETIVO}

Na hierarquia das necessidades ergonômicas e hedônicas, abaixo representada, as interações humano-tecnologia prazerosas são resultantes das necessidades hedônicas, cujos níveis mais altos só são atingidos após serem satisfeitas as necessidades ergonômicas de segurança, funcionalidade e usabilidade do produto/sistema.

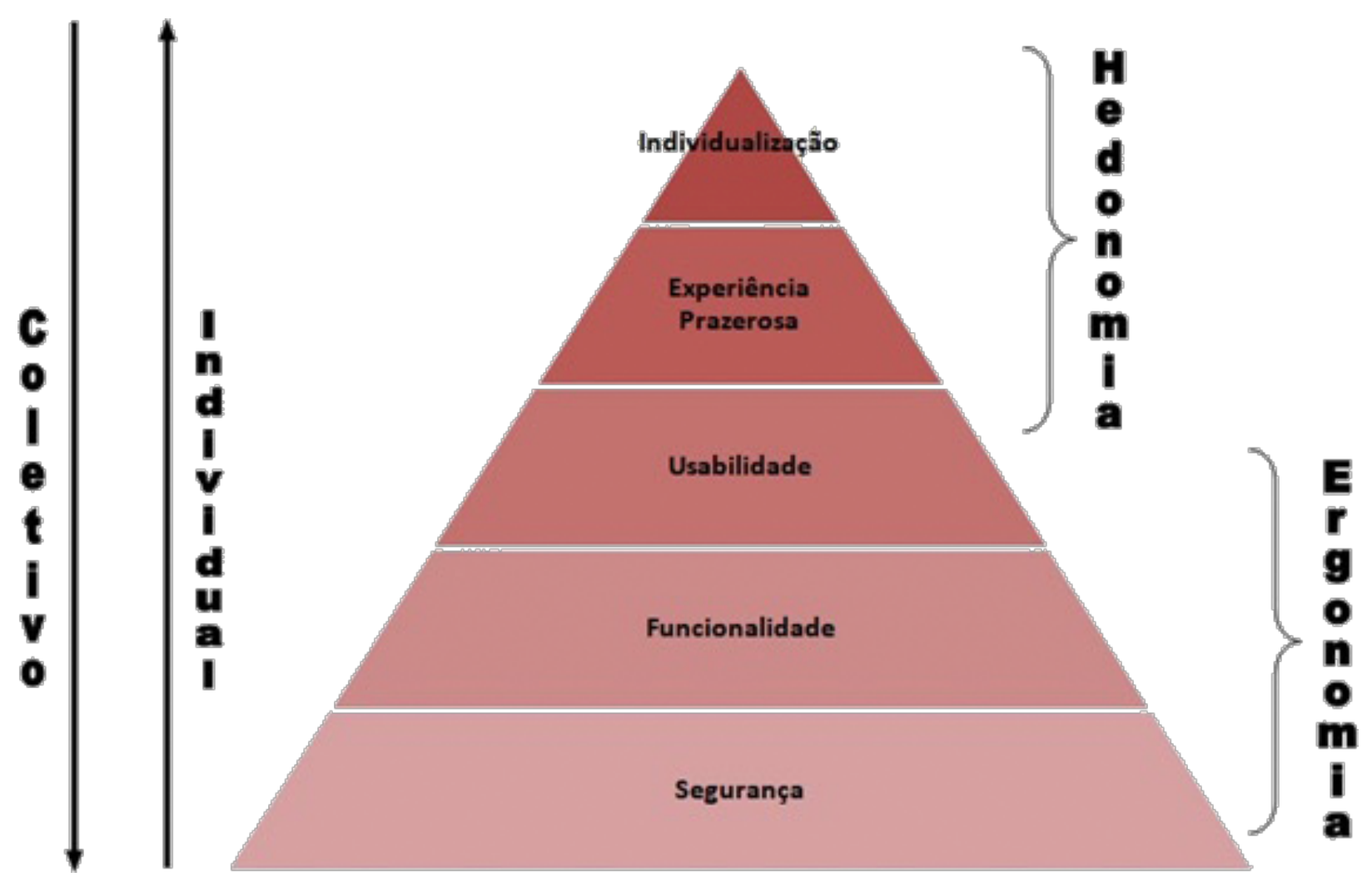

Caso esses critérios mínimos sejam atendidos, o processo de design segue para a fase do projeto da experiência do usuário, em que os benefícios emocionais devem ser considerados, sendo objetivo final a adaptação do sistema ao usuário, a facilidade de customização e a individualização pelo produto. 
Seguindo a hierarquia das necessidades ergonômicas e hedônicas na interação humano-tecnologia (CYBIS; BETIOL; FAUST, 2010), um produto/sistema deve ser projetado:

" Para operar em condições seguras, garantindo a integridade física do usuário e que este atinja o objetivo pretendido.

" Para garantir a usabilidade, que se caracteriza pela realização da tarefa de modo fácil e eficiente.

" Para atender às necessidades psicológicas e sociológicas do usuário, de modo que a interação se torne uma experiência prazerosa.

" Para incorporar princípios de customização que permitam que o sistema se adapte às características e preferências do usuário (individualização).

Nesses termos, o projeto ergonômico afetivo: não pode causar dano, dor ou sofrimento ao usuário; precisa funcionar, de modo a realizar aquilo a que foi destinado; e ter uma boa usabilidade (ser eficaz, eficiente, fácil de usar). Contudo, não basta ao produto ter uma boa usabilidade. É preciso que ele seja capaz de proporcionar prazer e de ajudar o usuário a alcançar a própria individualização.

O prazer e a individualização, dimensões hedônicas do projeto, só podem ser atingidos a partir de outro pilar da usabilidade, a satisfação do usuário, que é um resultado importante do design (usuários satisfeitos tendem a usar o produto novamente).
Conceituada pela ISO 9241:11 como "ausência do desconforto e presença de atitudes positivas para com o uso de um produto", a satisfação é de fundamental importância para o projeto com foco em experiências positivas, prazerosas e na individualização do usuário, apesar de não ser suficiente para explicar a percepção e a expectativa frente ao produto antes mesmo de adquiri-lo e/ou usá-lo.

Eis que surge, então, o interesse pela experiência do usuário, que a ISO 9241:210 conceitua como as "percepções e respostas da pessoa que resultam do uso ou da expectativa de uso de um produto, sistema ou serviço". (CYBIS; BETIOL; FAUST, 2010, p. 365)

Assim, ao se interessar pela experiência do usuário com o produto/sistema, o designer passa a se preocupar não só com o objeto físico, com a funcionalidade, com a interface e com a usabilidade. Passa a focar nos aspectos significativos e valiosos, positivos e prazerosos que irão viabilizar as conexões afetivas usuário-produto.

Como a busca pelo prazer é o principal foco do projeto hedônico, visto ser este o primeiro componente da hierarquia que não é compartilhado com a ergonomia, o produto hedonomicamente bem projetado irá proporcionar uma interação humano-tecnologia agradável, construída a partir da conexão emocional do usuário com o produto.

A individualização pelo produto (nível mais alto da dimensão hedônica) será alcançada caso o projeto viabilize a customização, que se destaca por maximizar a funcionalidade do sistema e o prazer do usuário, de 
modo a permiti-lo explorar as características pessoais, obter prazer e bem-estar em relação ao sistema.

Esse bem-estar, no entanto, não irá se restringir ao conforto, visto que, envolve outros aspectos, tais como: o significado pessoal atribuído ao produto/sistema, a manipulação dos dispositivos físicos e a modelagem do ambiente virtual, conforme as características e limitações dos usuários, que se combinam em um "processo dinâmico e adaptável". (NORMAN, 2008)

\section{A IMPORTÂNCIA DA EXPERIÊNCIA DO USUÁRIO PARA O PROJETO}

Antes mesmo que ocorra a relação física com o produto/sistema, o pretenso usuário constrói uma percepção/expectativa com base: em produtos similares, na opinião de outros usuários, na estética, e nas informações obtidas sobre o produto/sistema antes mesmo de adquiri-lo e/ou usá-lo.

Essa percepção/expectativa leva o consumidor a pesquisar sobre o produto/sistema e investigar as melhores opções do mercado a partir de preferências, gostos e interesses pessoais. 
Por ser "consequência do estado interno do usuário (predisposições, expectativas, necessidades, motivação, humor, etc), das características do sistema projetado (complexidade, objetivo, usabilidade, funcionalidade, etc.) e do contexto no qual a interação ocorre (configurações organizacionais/sociais, significado da atividade, espontaneidade do uso, etc.)" (HASSENZAHL; TRACTINSKY, 2006, p. 95), o foco do projeto ergonômico afetivo passa a ser a experiência do usuário.

Como a experiência do usuário envolve "o conjunto de todos os processos (físicos, cognitivos e emocionais) desencadeados no usuário a partir da sua interação com um produto ou serviço em diversos momentos (que incluem a expectativa da interação, a interação propriamente dita e a reflexão após a interação) em um determinado contexto de uso" (CYBIS; BETIOL; FAUST, 2010, p. 367), o produto hedonomicamente bem projetado irá integrar o modo como os usuários respondem física, cognitiva e emocionalmente às propriedades (funcionais, estéticas e de interação) dos produtos e sistemas.

Essas propriedades, ao serem associadas às memórias e sentimentos do usuário, tornam a interação humano-tecnologia significativa e valiosa o suficiente a ponto de favorecer conexões positivas entre $o$ usuário e o produto.

Levando-se em consideração as demandas pessoais é possível integrar as características dos usuários à tarefa de modo que eles possam se reconhecer por meio da interface, que viabiliza as conexões emocionais com o produto/sistema. 
Em síntese, no design hedônico o designer não se preocupa apenas com o objeto físico, a funcionalidade, a interface e a usabilidade. Contudo, por ser um aspecto do projeto que é compartilhado tanto com a ergonomia quanto com a hedonomia, a usabilidade recebe uma atenção especial.

Como o bom projeto respeita as recomendações ergonômicas e os aspectos relacionados à usabilidade (MONT'ALVÃO; DAMAZIO, 2012), a satisfação e o conforto, metas da usabilidade, tornam-se fundamentais para o projeto que se concentra na experiência prazerosa, o que será discutido na próxima seção.

\section{PROJETO E DESENVOLVIMENTO DE INTERFACES PRAZEROSAS}

Em seus primórdios, era comum a influência de teorias e modelos cognitivos humanos no projeto e avaliação de interfaces. Com o passar dos anos essa realidade foi se modificando e passou a agregar as recomendações ergonômicas.

Recentemente, avanços significativos vêm sendo observados no campo metodológico da usabilidade, cujo ciclo evolutivo, iterativo e 
baseado na participação do usuário, antes regulado pela norma ISO $13407^{02}$, trata do projeto centrado no usuário (CYBIS; BETIOL; FAUST, 2010), atualmente regulado pela ISO 9241 - 210: $2019^{03}$.

Esse aspecto não determinístico do projeto requer a máxima atenção por parte do desenvolvedor quanto aos requisitos de usabilidade. Como a usabilidade ocupa-se da interface (que é operada por diversos tipos de usuários, com opiniões, necessidades, gostos, expectativas e interesses variados), a avaliação com foco no usuário passa a ser fundamental para o projeto.

Com foco na experiência positiva e prazerosa, a avaliação do design hedônico se concentra em como o usuário avalia a experiência com o produto/sistema. Esse momento do projeto demanda que o designer investigue não só a experiência falada, mas principalmente a experiência sentida, o que requer "conhecimentos, abordagens, métodos e ferramentas especializados, muitos dos quais ainda em desenvolvimento". (CYBIS; BETIOL; FAUST, 2010, p. 19)

Também é nesse momento que o usuário, participante ativo do processo de design, fornece informações sobre as versões da interface de modo a colaborar, inclusive, com algumas decisões do projeto. (CYBIS; BETIOL; FAUST, 2010)

Fundamental para o desenvolvimento de produtos/sistemas com alta qualidade de uso, a avaliação possibilita identificar problemas na interface e na interação que afetam negativamente a qualidade da experiência do usuário. Com esses cuidados, é possível verificar se a interface satisfaz aos requisitos antes mesmo de ser implementada e comercializada.

\section{INTEGRANDO ASPECTOS DA USABILIDADE E EXPERIÊNCIA DO USUÁRIO AO PROJETO}

Para se projetar um produto/sistema faz-se necessário, entre outros aspectos, entender as necessidades do usuário. Uma parte desse processo está relacionada à avaliação do produto/sistema a partir de metas da usabilidade (segurança, eficácia, eficiência, facilidade no uso).

02 https://www.abntcatalogo.com.br/norma.aspx?ID=26053

03 https://www.abntcatalogo.com.br/norma.aspx?ID=419228 
Essas metas orientam os desenvolvedores para a observância de questões específicas no projeto e transformam-se em critérios de usabilidade, tais como: tempo para completar uma tarefa (eficiência), tempo para aprender uma tarefa (facilidade para aprender) ou o número de erros cometidos pelo usuário durante a realização da tarefa em um dado período de tempo (facilidade para recordar). (PREECE; ROGERS; SHARP, 2005)

Como a usabilidade, a experiência do usuário, a acessibilidade e a comunicabilidade são critérios de qualidade relacionados ao uso (BARBOSA; SILVA, 2010), esses critérios passam a auxiliar as decisões de design de modo a contribuir na verificação da adequação do produto aos usuários de modo que eles possam atingir seus objetivos em contextos de uso.

Além desses aspectos, os critérios de uso também possibilitam verificar se o produto/ sistema atende aos requisitos do projeto, como se comporta e quais os impactos disso na experiência do usuário.
Devido ao fato das metas da usabilidade não serem suficientes para alcançar a individualização pelo produto e, consequentemente, atingir o nível máximo da hierarquia das necessidades ergonômicas e hedônicas (ver figura 1), faz-se necessário focar na experiência prazerosa, que destaca-se por ser o nível da hierarquia que não é compartilhado com a ergonomia.

Dito de outra forma, o produto/sistema hedonomicamente bem projetado requer que a avaliação não se restrinja às metas da usabilidade. Como exemplo, podemos citar os produtos/sistemas de Realidade Virtual (RV), que tanto apresentam dispositivos físicos quanto componentes virtuais. (TORI; HOUNSELL, 2018; FIALHO, 2018; TORI; KIRNER, 2006) Nesse caso, ainda que seja necessária mais força que a habitual para fazer uso de um dispositivo háptico, a avaliação do produto/sistema pode resultar numa experiência divertida e agradável ao serem consideradas as metas da experiência do usuário. 


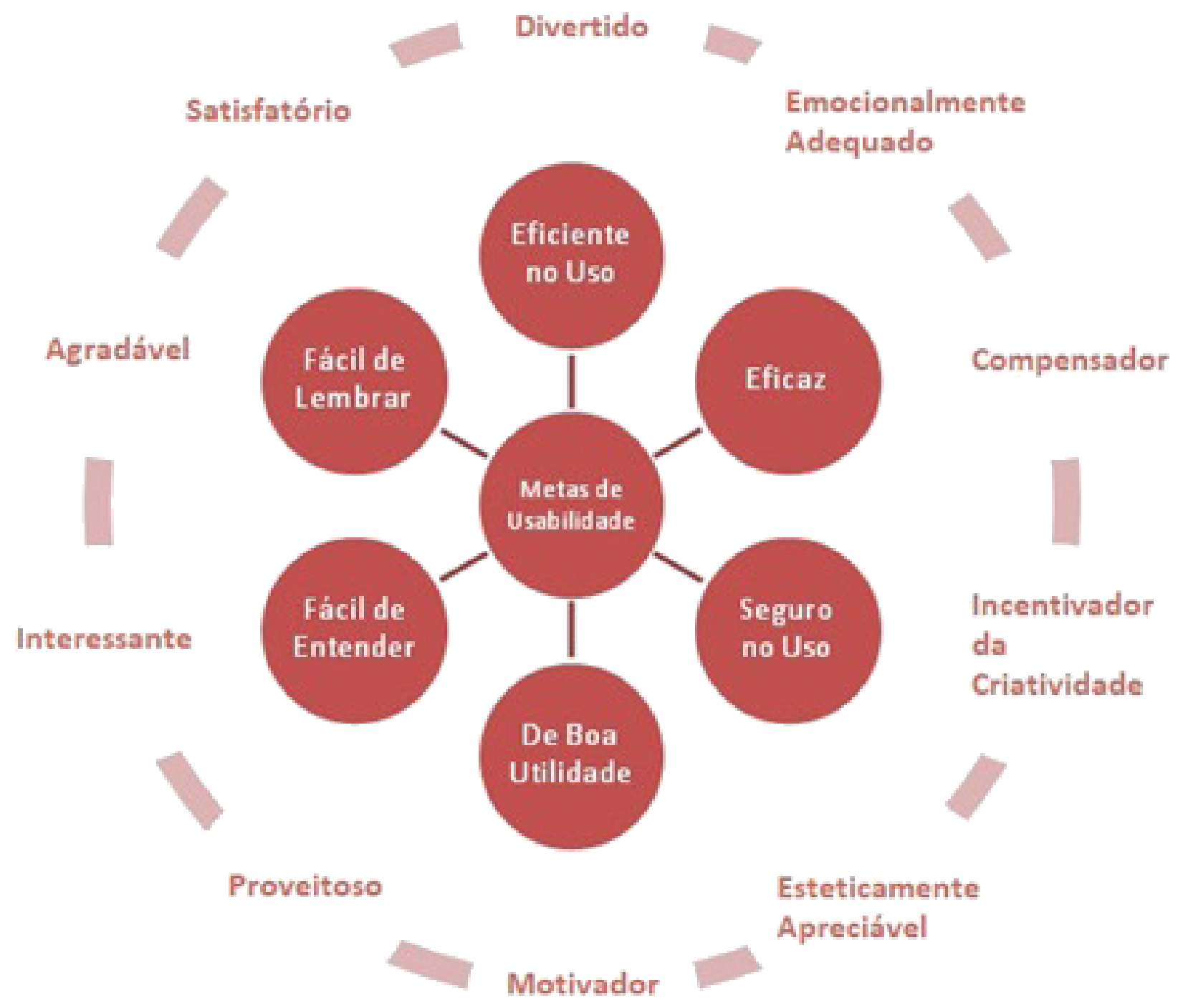

Face ao exposto, é possível ao designer perguntar-se: Quais seriam as metas da experiência do usuário? Por que elas seriam relevantes para o projeto ergonômico afetivo? Quando utilizá-las?

Figura 2.

Fundamentais para o projeto ergonômico afetivo, as metas da experiência do usuário preocupam-se em explicar a qualidade da experiência ( $\mathrm{x}^{\mathrm{O}}$ : divertida, agradável) e estão relacionadas ao modo como o usuário se sente na interação com o sistema.

Algumas metas, contudo, são incompatíveis, pois nem tudo é possível ou desejável para o projeto. Cabe então ao designer/ergonomista propor combinações de ambas as metas, sempre observando

Relação das metas da usabilidade com as metas da experiência do usuário. Fonte: França (2019). Adaptado de Preece; Rogers; Sharp (2005). 
quem será o público-alvo, qual a tarefa a ser realizada e em que contexto de uso. (PREECE; ROGERS; SHARP, 2005)

Ou seja, no projeto ergonômico afetivo não cabe apenas a ênfase no desempenho. É preciso, principalmente, avaliar os aspectos hedônicos. Como a usabilidade e a experiência do usuário são critérios de qualidade relacionados ao uso, faz-se necessária a combinação das metas de usabilidade com as metas da experiência do usuário de modo que o sistema possa atender às necessidades psicológicas e sociológicas do usuário (experiência prazerosa) e se adaptar às características e preferências dos usuários (individualização).

Desse modo é possível projetar para que o produto/sistema adquira um significado pessoal, tornando-se valioso para o usuário a ponto dele estabelecer conexões afetivas positivas com o produto/sistema.

\section{ETAPAS DO PROCESSO DE DESIGN NUMA PERSPECTIVA HEDÔNICA}

A incessante busca por critérios verificáveis e mensuráveis é uma questão central ao design hedônico e tem como características: (1) especificar medidas quantificáveis relacionadas à experiência emocional do usuário com o produto/sistema, (2) que são documentadas no projeto e desenvolvimento do produto/sistema, (3) para uma avaliação do produto/sistema relacionando-o a tais medidas.

Fundamentado em uma perspectiva holística e com uma descrição detalhada, o ciclo das atividades do projeto - análise dos requisitos, projeto, desenvolvimento e testagem das versões da interface - será, a seguir, identificado e descrito. (FRANÇA, 2019) 

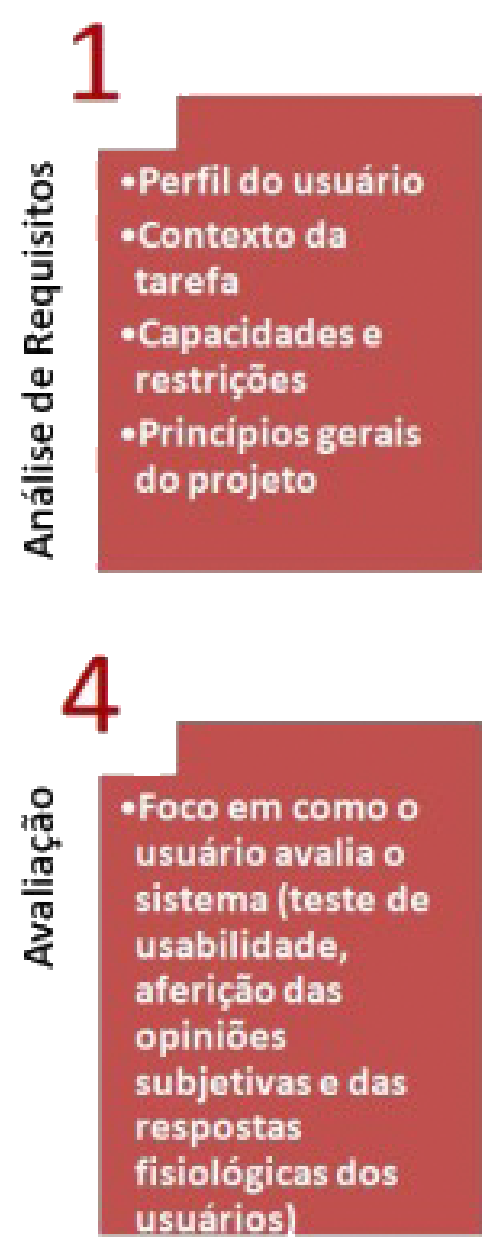
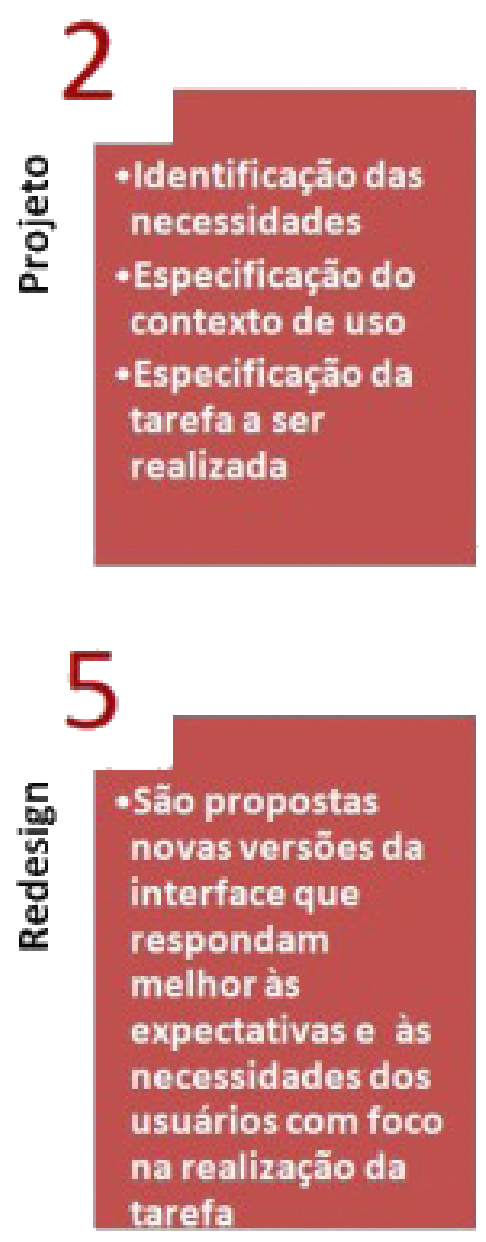
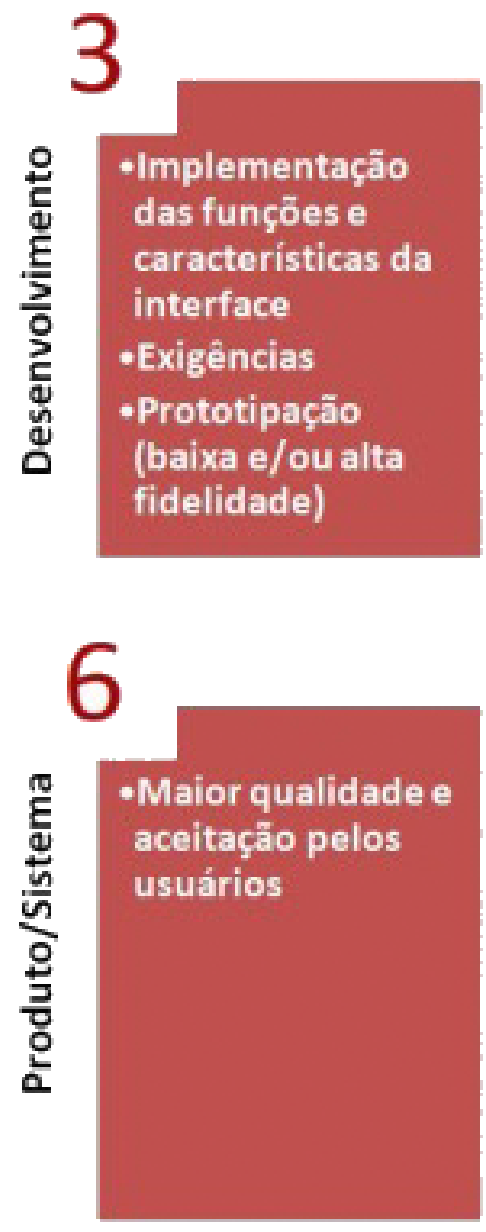

\section{FASE 1: ANÁLISE DOS REQUISITOS}

Por ser mais inicial, essa fase contempla a identificação: do perfil do usuário (público-alvo); do contexto da tarefa; das capacidades e restrições; e dos princípios gerais do projeto.

Como deve respeitar a sequência da hierarquia das necessidades ergonômicas e hedônicas, as etapas iniciais precisam satisfazer as necessidades ergonômicas de segurança, funcionalidade e usabilidade.

Nesse sentido, a fase de análise dos requisitos precisa considerar os requisitos

Figura 3.

Ciclo de vida do projeto hedônico. Fonte: França (2019) 
ergonômicos, ainda que eles não sejam exclusivos e/ou determinantes. Segundo Mont'Alvão e Damazio (2012, p. 20-21), são exemplos de requisitos ergonômicos: conforto postural, adequação dimensional, segurança no uso, facilidade de manipulação, compatibilidade de movimentação, minimização de esforços acionais, racionalização e funcionalidade do arranjo físico dos componentes, facilitação da manutenção, apropriação do campo visual, legibilidade, visibilidade e compreensibilidade dos caracteres alfa-numéricos e dos símbolos iconográficos, objetivação da tarefa e contexto de uso.

Nessa fase também ocorre a especificação do contexto de uso, com o intuito de identificar o tipo de usuário para quem a interface será desenvolvida; o tipo de tarefa e as condições ambientais em que a interface será utilizada (equipamento, dispositivos, ambientes: físico, virtual e organizacional); e as exigências para a usabilidade ${ }^{04}$ do produto/sistema.

Como prioriza a ligação afetiva do usuário com o produto/sistema, a usabilidade deve destacar bem mais como o usuário avalia ao invés de avaliar o usuário. Para tal, é preciso levar em consideração as características humanas: afetivas, cognitivas, sensoperceptivas e comportamentais a serem identificadas no projeto.

04 Qualitativas (funções e características da interface que deveriam ser implementadas para atender àquele tipo de usuário, tarefa e tecnologia anteriormente especificada e que serão considerados no projeto e na avaliação do sistema) e quantitativas (nível de usabilidade esperado: valores mínimos admissíveis de eficácia, eficiência e satisfação do usuário). Caso não atenda aos valores mínimos admissíveis, faz-se necessário o redesign do produto/sistema. 


\section{FASE 2: PROJETO}

Diferente da Análise de Requisitos, que identifica as características do projeto de modo mais abrangente e genérico, a fase 2 , que é o projeto propriamente dito, caracteriza-se por ser mais específica e detalhada.

Nessa fase, busca-se identificar as necessidades psicológicas e sociológicas do usuário, que Mont'Alvão e Damazio (2012, p. 27) identificam como "necessidades de pertencer, alcançar, ser competente e independente (no uso do sistema)" e que Hancock, Pepe e Lauren (2005) identificam como necessidades de pertencimento, realização, competência e independência.

Mais especificamente, são identificadas as necessidades do usuário a serem enfatizadas pelo produto/sistema (FRANÇA, 2019): independência; orgulho; confiança; coragem; poder; justiça; realização; reconhecimento/ valorização; recordação; solução de problemas; motivação; diversão; pertencimento social e imagem pessoal.

Também nessa fase são comuns perguntas: Como projetar para a experiência positiva do usuário? Quais seriam as necessidades afetivas do usuário? Em que medida o produto/sistema estaria impactando a motivação e a satisfação do usuário? Que aspectos do projeto contribuem para o estabelecimento de conexões afetivas e para a otimização da relação humano-tecnologia?
Com o intuito de atingir a individualização, nível mais elevado do design hedônico, faz-se necessário considerar a adaptabilidade do produto/sistema ao usuário e a facilidade de customização, que são considerados na especificação e no detaIhamento da tarefa.

A adaptabilidade do produto/sistema ao usuário inclui, entre outros aspectos, a conformidade às necessidades do usuário e às metas da experiência do usuário. A facilidade de customização deve levar em consideração as características do usuário, o controle do usuário e as ações explícitas (por meio do feedback, por exemplo).

As características do usuário dizem respeito: à faixa-etária (se são crianças, jovens, adultos ou idosos); nível de expertise do usuário (conhecimentos prévios); limitações físicas, cognitivas, psicossociais e/ou motoras; poder aquisitivo; etc.

O controle do usuário está relacionado ao grau de confiança, liberdade e independência proporcionado pelo sistema, o que contribui para uma maior autonomia do usuário.

As ações explícitas caracterizam-se pela relação explícita entre uma ação do usuário e um processamento do sistema, o que favorece uma melhor compreensão do funcionamento do sistema, a menor ocorrência de erros e que os usuários aprendam melhor. 


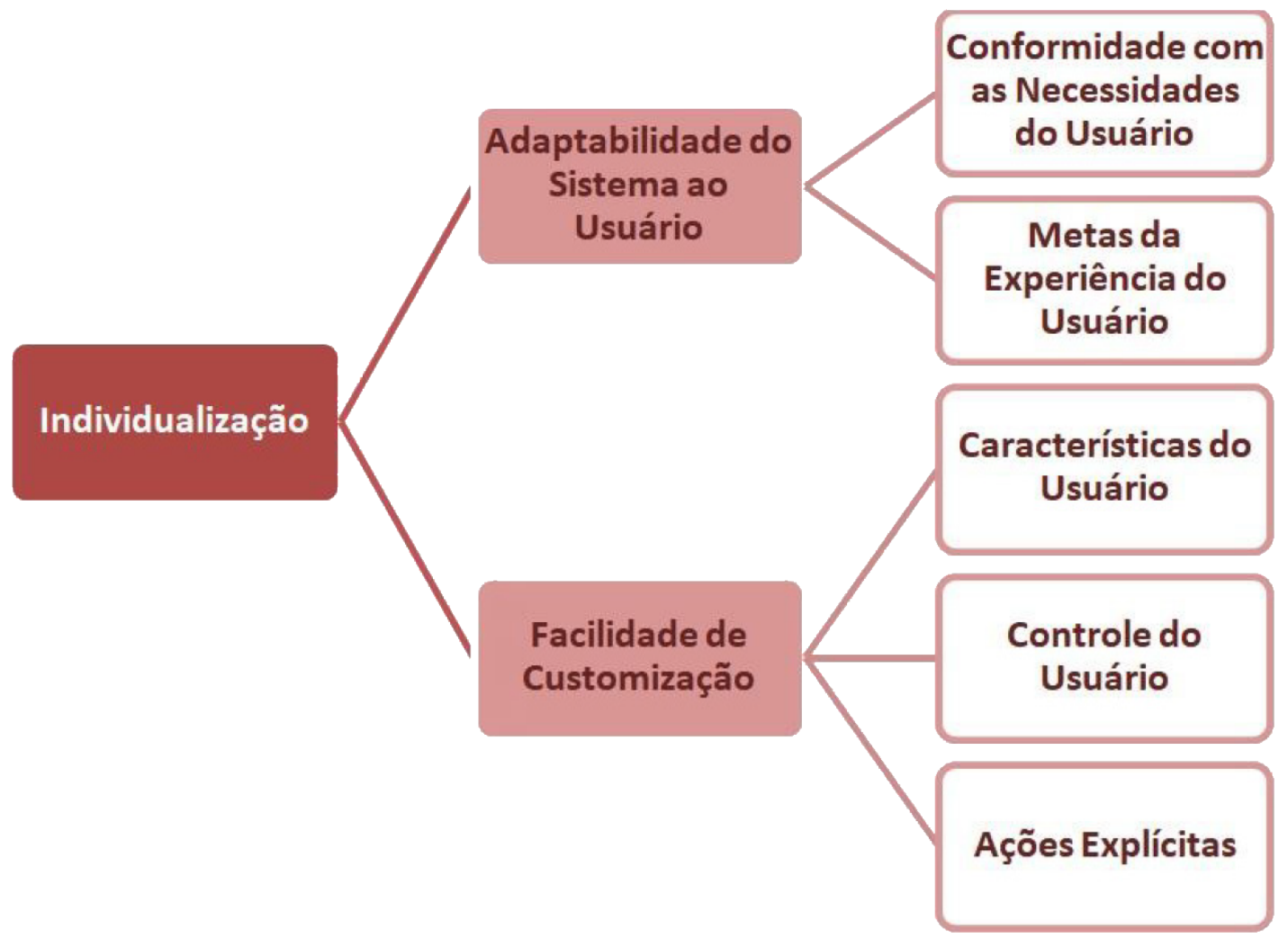

Com base nesses critérios é possível obter medidas, minimizar as ambiguidades e classificar as qualidades desejáveis para que o design do sistema favoreça o prazer e a individualização do usuário.

\section{FASE 3: DESENVOLVIMENTO}

Figura 4.

Critérios para a individualização no Projeto Ergonômico Afetivo. Fonte: França (2019). Adaptado de Cybis, Betiol e Faust (2010).
Caracteriza-se pela implementação de aspectos da interface física e/ ou virtual que favoreçam ligações afetivas usuário-sistema positivas e prazerosas e a individualização do usuário.

Com foco na adaptabilidade do sistema ao usuário e na facilidade de customização são implementados, nesta fase, os elementos da interface e suas respectivas funções, o que também inclui a modelagem do personagem que representa o público-alvo do sistema.

Por meio das metáforas na interface, o desenvolvedor comunica algo desconhecido ou abstrato para o usuário recorrendo a outro objeto, mais conhecido ou familiar para o usuário. Essas representações permitem simulações do mundo físico (sem que pessoas, 
coisas e ambientes estejam literalmente dentro do computador), embora estejam metaforicamente (virtualmente, digitalmente) presentes no sistema.

A metáfora precisa comunicar. Nesse caso, a metáfora pode ser classificada como positiva ou negativa.

É positiva quando: faz sentido, tanto para o desenvolvedor, quanto para o usuário; quando está adequada ao contexto de uso, permitindo que o usuário se concentre naquilo que realmente precisa ser feito; quando o objeto representado retrata apenas as principais características do objeto original, aquelas que se quer destacar, ressaltar; e quando o usuário percebe a interface como sedutora, segura e previsível.

É negativa quando: é complexa a ponto de complicar a execução da tarefa, aumentando a carga mental, interferindo na eficiência do usuário; e quando desvia o foco da atenção, dificultando a concentração durante a execução da tarefa, interferindo na eficácia do usuário.

A estética da interface deve favorecer a percepção positiva do sistema, o foco/manutenção da atenção, o interesse e a aprendizagem (mais familiar para o usuário; interface mais intuitiva). As melhores metáforas são aquelas que aumentam a performance (desempenho) do usuário (facilidade de aprendizado para os usuários iniciantes e facilidade de uso para os usuários avançados).

Além desses aspectos, extremamente relevante ao projeto ergonômico afetivo é o conceito de Affordances Hedônicas. Também conhecidas como propriedades 
afetivas, as affordances hedônicas desencadeiam reações emocionais nos usuários por meio dos atributos físicos e das metáforas (atributos virtuais) da interface. Essa reação emocional é o resultado da avaliação da situação e da percepção da interface como algo agradável, divertido, prazeroso.

São exemplos de atributos do produto/sistema que favorecem a emergência de afetos positivos: "rostos sorridentes; calor; conforto; sabores doces; cheiros agradáveis; matizes brilhantes e altamente saturadas; música e sons harmoniosos; batidas rítmicas; formas simétricas, redondas e suaves; e a avaliação da situação que indica que o usuário percebe alto nível de controle da situação". (HANCOCK; PEPE; MURPHY, 2005, p. 12)

Em contrapartida, alguns atributos desencadeiam afetos negativos nos usuários do produto/sistema, tais como: "escuridão; sons ásperos e abruptos; ruídos alarmantes; sobrecarga de informação; sabores amargos; objetos pontiagudos; cheiros podres; alimentos em decomposição; luzes repentinas e brilhantes; temperaturas extremas; percepção de falta de controle; e pressão pelo tempo". (HANCOCK; PEPE; MURPHY, 2005, p. 12)

Tradicionalmente, as affordances perceptivas estão relacionadas 
às metas de usabilidade. No projeto ergonômico afetivo, as affordances hedônicas são relacionadas às metas da experiência do usuário. Cabe às pesquisas empíricas "relacionarem esses atributos à experiência do usuário". (HANCOCK; PEPE; MURPHY, 2005, p. 12)

São recomendações de design no projeto hedônico: motivação; qualidade de vida; diversão; e prazer. (HANCOCK; PEPE; MURPHY, 2005)

Cabe ao designer considerar os fatores motivacionais com foco na gamificação. (BUSARELO, 2016; HAMARI, 2015)

\section{FASE 4: AVALIAÇÃO}

Caracteriza-se pelo foco em como o usuário avalia o produto/sistema. Nesta fase são comuns perguntas do tipo: Como aferir o prazer no uso do sistema? Como identificar se a experiência do usuário está sendo positiva, prazerosa? Em que medida essa experiência positiva, prazerosa proporciona bem-estar ao usuário? O que foi medido é similar ao que foi previsto?

Leventhal e Barnes (2008) alertam que a habilidade da pessoa perceber a informação em uma interface é um ponto crucial para a habilidade de usar a interface. Ainda conforme as autoras, 
"interfaces que contêm pistas perceptíveis e que oferecem feedback dão maior suporte à facilidade de uso e à facilidade para aprender do que aquelas que não o fazem" (LEVENTHAL; BARNES, 2008, p. 43)

Quanto às respostas do usuário:

» Respostas cognitivas (avaliação e decisão): testa-se a carga mental (esforço) do usuário na interação humano-tecnologia (eficiência do usuário);

" Respostas emocionais (avaliação e julgamento): verifica-se a experiência do usuário com o produto/sistema (experiência prazerosa $x$ não-prazerosa): adequação do produto/ sistema às metas da experiência do usuário (incentiva a criatividade, emocionalmente adequado, divertido, compensador, esteticamente apreciável, motivador, proveitoso, interessante, agradável) a fim de proporcionar experiências positivas e prazerosas aos usuários;

" Ação (sentimentos e atitudes do usuário - respostas aprendidas): verifica a rapidez (eficiência) e o sucesso (eficácia) do usuário na realização da tarefa. Nesse caso, são comuns perguntas como: As ações do usuário são realizadas de forma clara, simples e rápida? O usuário consegue fazer o que precisa? O usuário fica frustrado enquanto executa a tarefa? 
Com o Modelo de Avaliação do Projeto Ergonômico Afetivo (FRANÇA, 2019), é possível ao designer/ergonomista operacionalizar variáveis em um conjunto de medidas e entender como essas medidas podem ser interpretadas.

As medições podem ser (1) qualitativas: observação do usuário, adequação da interface à tarefa, flexibilidade da interface para se adequar às características do usuário e escalas de satisfação do usuário, e/ou (2) quantitativas: aferição das respostas fisiológicas dos usuários antes e após ou durante o uso do sistema, facilidade para aprender, usar e reaprender (variáveis de desempenho: velocidade, acurácia e taxa de erros) e facilidade de uso (carga mental: interface mais ou menos intuitiva).

Como resultados indesejáveis de uma relação humano-tecnologia não prazerosa, é possível identificar "a dificuldade em completar as tarefas, ou até mesmo em concentrar-se" e a falta de "motivação por parte do usuário em interagir com o sistema" (MONT'ALVÃO; DAMAZIO, 2012, p. 28), que não se restringem à usabilidade. São resultado das questões afetivas e dos prejuízos/benefícios emocionais da interação humano-tecnologia. 


\section{FASE 5: REDESIGN}

Caracteriza-se pelo redesign do sistema no qual são propostas novas versões da interface que respondam melhor às expectativas e às necessidades dos usuários.

A partir dos resultados obtidos na avaliação, é elaborado um relatório que inclui as considerações do ergonomista sobre cada item avaliado pelo usuário, seguido pelas recomendações ergonômicas para a meIhoria desses itens. Em seguida é proposto o redesign do sistema, a partir do qual são modificados e/ou incluídos elementos e funções, considerando o que foi sugerido nas recomendações ergonômicas. Após ser implementada a nova versão, sugere-se testar o produto/sistema novamente. Esse procedimento pode ser repetido quantas vezes forem necessárias.

\section{SOBRE A AVALIAÇÃO NO DESIGN HEDÔNICO}

Com foco nas limitações de tempo e de custo, o projeto e desenvolvimento de produtos/sistemas envolve a participação do usuário, tanto para informar quanto para avaliar, e até mesmo como coautor nas soluções de design.

Caracterizado pelo ciclo requisitos-projeto-desenvolvimento-avaliação-redesign, o projeto hedônico considera os aspectos da engenharia de usabilidade e vai além, possibilitando ao designer explorar ideias alternativas para propor novas versões da 
interface, elaboradas e refinadas nos ciclos de avaliação e redesign até chegar à solução, que é o produto/sistema final, pronto para ser comercializado.

Como o projeto hedônico é um projeto centrado no indivíduo, na pessoa que percebe e que sente, faz-se necessário que a experiência do usuário, ainda que subjetiva, seja medida e quantificada a partir de comportamentos e atitudes (TULLIS; ALBERT, 2008).

Essa aferição contribui para o desenvolvimento e redesign, cuja avaliação deve contemplar tanto a experiência relatada quanto a experiência sentida pelos usuários de modo a ser possível adequar o produto/ sistema às características de cada um por meio da customização.

Desse modo é possível superar a uniformidade do produto (NORMAN, 2008), cujos atributos são associados às experiências passadas, presentes e às expectativas do usuário, que na interação humano-tecnologia adquirem um significado pessoal e tornam o produto/sistema afetivamente valioso. 


\section{CONSIDERAÇÕES FINAIS}

Como os avanços tecnológicos nem sempre proporcionam resultados positivos para a saúde, segurança e conforto dos usuários, faz-se necessário considerar os fatores humanos/ergonômicos, a funcionalidade e a usabilidade do produto/sistema, que são a base do projeto ergonômico afetivo.

Por priorizar a dimensão hedônica no ciclo requisitos-projeto-desenvolvimento-avaliação-redesign, o projeto ergonômico afetivo recorre às características e limitações do usuário enquanto considera a percepção, as expectativas e as respostas emocionais dos usuários em relação ao produto/sistema.

Desse modo, além de desenvolver produtos/sistemas eficazes, eficientes e fáceis de usar, o projeto ergonômico afetivo se adapta às características e preferências do usuário, que contribuem para uma melhor experiência e, consequentemente, para uma maior aceitação do produto/sistema pelo consumidor.

Devido às emoções e sensações provocadas pela experiência proporcionarem prazer e bem-estar, a avaliação do usuário pode ser positivamente impactada a tal ponto que, além de atraído, o usuário se torne fidelizado ao produto/sistema. 


\section{AGRADECIMENTOS}

À CAPES - Coordenação de Aperfeiçoamento de Pessoal de Nível Superior, pelo apoio através da bolsa concedida.

\section{REFERÊNCIAS}

BARBOSA, S. D. J.; SILVA, B. S. Interação Humano-Computador. Rio de Janeiro: Elsevier, 2010.

BUSARELLO, R. I. Gamification: Princípios

e Estratégias. São Paulo: Pimenta Cultural, 2016.

CYBIS, W.; BETIOL, A. H.; FAUST, R.

Ergonomia e Usabilidade: Conhecimentos, Métodos e Aplicações. São Paulo: Novatec Editora, 2010.

FALCÃO, C.; SOARES, M. Usabilidade de Produtos de Consumo: Uma Análise dos Conceitos, Métodos e Aplicações. Estudos em Design, v. 21, n. 2, 2013.

EDELBERG, R. Electrical ActivityoftheSkin: Its Measurement andUses in

Psychophysiology. InN. S. Greenfield \&R. A. Sternbach(Eds.), Handbook of Psychophysiology (pp. 367-418). New York: Holt, 1972.

FACCHINI,L. A. UmaContribuição da Epidemiologia: oModelo de Determinação Social AplicadoàSaúdedoTrabalhador. In: BUSCHINELLI, J. T.; ROCHA, L. E.;RIGOTO, R. M. Vida,Doença eTrabalhador no Brasil.Riode Janeiro, Vozes, 1994.

FALCÃO, C.; SOARES, M.

UsabilidadedeProdutos de Consumo: UmaAnálisedos Conceitos, Métodos e Aplicações. Estudos em Design, v. 21, n. 2, 2013. 
FERRARI,E. A. M. etal. Plasticidade Neural: Relações comoComportamentoeAbordagens Experimentais. Psicologia:TeoriaePesquisa, Vol. 17n. 2, Mai-Ago2001.

FIALHO, A. B. RealidadeVirtualeAumentada: Tecnologias para AplicaçõesProfissionais. São Paulo: Érica, 2018.

FISCHER, F. M. Impactosdo Trabalho emTurnoseNoturno na SaúdeeBem-Estar do Motorista Profissional.In: SeminárioErgonomia eQualidadedeVidanoSetor deTransporte: ColetâneadeTextos Técnicos. Brasília: SEST/SENAT, 2001.

FORSYTHE, C. et al. Cognitive Neuroscience of Human Systems: Work and Everyday Life. Boca Raton, FL: CRC Press, 2015.

FRANÇA, A. C. P. Selfdigital:explorações acerca daconstruçãodo"eu" nainternet. Dissertação[Mestrado]. Pós-graduaçãoemPsicologia Cognitiva,Universidade Federal de Pernambuco, Pernambuco, 2008.176 p.

Bem-vindosàMatrix:Questões Sobre Cultura, Self,Subjetividade, RealidadeeMundos Paralelos emTecnologias Digitais. XI CongressolnternacionaldeTecnologia na Educação. Recife, PE, 2013.

FRANÇA, A. C. P. Biofeedback e Regulação Emocional: um estudo sobre a emoção aplicada a sistema de treinamento em Realidade Virtual. Tese [Doutorado]. Pós-graduação em Design, Centro de Artes e Comunicação, Universidade Federal de Pernambuco, Pernambuco, 2019.

GARCIA-MOLINA, G.; TSONEVA, T.; NIJHOLT, A. Emotional

Brain-Computer Interfaces. Int. J. Autonomous and Adaptive Communications Systems, Vol. 6, No. 1, 2013.

HANCOCK, P. A.; PEPE, A. A.; MURPHY, L. L. Hedonomics: The Power of Positive and Pleasurable Ergonomics. Ergonomics in Design, vol. 13, n. 1, 2005.

HAMARI, J. Gamification: Motivations \& Effects. Aalto University publication series. Doctoral Dissertations. Finland: School of Business, 2015.

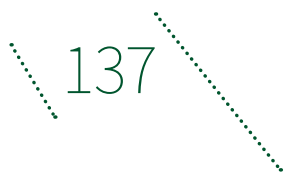


HASSENZAHL, M.; TRACTINSKY, N. User

Experience - A Research Agenda. Editorial. Behavior \& Information Technology, v. 25, n. 2, March - April, p. 91 - 97, 2006.

ISO 9241:11. Requisitos Ergonômicos para Trabalho de Escritórios com

Computadores: Parte 11 - Orientações sobre Usabilidade, 1998.

ISO 9241:210. Ergonomics of Human-System Interaction. Part 210: Human-Centered Design for Interactive Systems, 2010.

ISO 9241-210. Ergonomics of human-system interaction. Part 210: Human-Centred Design for Interactive Systems, 2019.

JOHNSON, A.; PROCTOR, R. W.

Neuroergonomics: A Cognitive

Neuroscience Approach to Human Factors and Ergonomics. New York: Palgrave Macmillan, 2013.

LEVENTHAL, L.; BARNES, J. Usability

Engineering: Process, Products and

Examples. New Jersey: Pearson Education, 2008.

MONT'ALVÃO, C.; DAMAZIO, V. Orgs. Design, Ergonomia, Emoção. Rio de Janeiro: Mauad X: FAPERJ, 2012.

NORMAN, D. Design Emocional: Por que Adoramos (ou Detestamos) os Objetos do Dia a Dia. Rio de Janeiro: Rocco, 2008.

PREECE, J.; ROGERS, Y.; SHARP, H. Design de Interação: Além da Interação HomemComputador. Porto Alegre: Bookman, 2005.
RACHED, T. S.; PERKUSICH, A. Emotion Recognition Based on Brain-Computer Interface Systems. Disponível em: https:// cdn.intechopen.com/pdfs-wm/44926.pdf Acesso em 12/06/2017.

SANTA ROSA, J. G.; PEREIRA JR, A.; LAMEIRA, A. P. Neurodesign: o Cérebro e a Máquina. Rio de Janeiro: Rio Book’s, 2016.

TORI, R.; HOUNSELL, M. S. (Org.) Introdução à Realidade Virtual e Aumentada. Porto Alegre: SBC, 2018.

TORI, R.; KIRNER, C. Fundamentos de Realidade Virtual. In: TORI, R.; KIRNER, C.; SISCOUTTO, R. Fundamentos e Tecnologia de Realidade Virtual e Aumentada. Livro do Pré-simpósio, VIII Symposium on Virtual Reality. Porto Alegre: Editora SBC, 2006.

TULLIS, T.; ALBERT, B. Measuring the User Experience: Collecting, Analysing and Presenting Usability Metrics. USA: Elsevier, 2008.

VAN DER LINDEN, J. Ergonomia e Design: Prazer, Conforto e Risco no Uso de Produtos. Porto Alegre: Ed. UniRitter, 2007. 
139 